\title{
Low cycle fatigue behavior and fracture mechanism of a directionally solidified CM247 LC superalloy
}

\author{
Behnam Salehnasab ${ }^{1}$ and Esmaeil poursaeidi ${ }^{2}$ \\ ${ }^{1}$ Iran University of Science and Technology \\ ${ }^{2}$ University of Zanjan
}

August 28, 2020

\begin{abstract}
In gas turbines, superalloys are exposed to thermal as well as mechanical cyclic loadings during start-up and shut down processes, which can accelerate the formation of fatigue failure mechanisms. In the present study, low cycle fatigue behavior and fracture mechanism of a directionally-solidified CM247 LC superalloy at two temperatures of $600{ }^{\circ} \mathrm{C}$ and $800{ }^{\circ} \mathrm{C}$ were investigated. For this purpose, strain-controlled low cycle fatigue tests were carried out at $600{ }^{\circ} \mathrm{C}$ and $800{ }^{\circ} \mathrm{C}$, and constant total strain amplitudes of $0.4,0.6,0.8$, and $1 \%$ were applied during the totally reversed loading ratio $(\mathrm{R}=-1)$. The Coffin-Manson model, based on plastic deformation and a model based on the hysteresis energy criterion is used to predict fatigue life and evaluate the low cycle fatigue behavior. SEM observations of the surface of the failed specimen showed similar LCF failure mechanisms in all the strain amplitudes and temperatures.
\end{abstract}

\begin{abstract}
In gas turbines, superalloys are exposed to thermal as well as mechanical cyclic loadings during start-up and shut down processes, which can accelerate the formation of fatigue failure mechanisms. In the present study, low cycle fatigue behavior and fracture mechanism of a directionally-solidified CM247 LC superalloy at two temperatures of $600{ }^{\circ} \mathrm{C}$ and $800{ }^{\circ} \mathrm{C}$ were investigated. For this purpose, strain-controlled low cycle fatigue tests were carried out at $600{ }^{\circ} \mathrm{C}$ and $800{ }^{\circ} \mathrm{C}$, and constant total strain amplitudes of $0.4,0.6,0.8$, and $1 \%$ were applied during the totally reversed loading ratio $(R=-1)$. The Coffin-Manson model, based on plastic deformation and a model based on the hysteresis energy criterion is used to predict fatigue life and evaluate the low cycle fatigue behavior. SEM observations of the surface of the failed specimen showed similar LCF failure mechanisms in all the strain amplitudes and temperatures.
\end{abstract}

Keywords: Low cycle fatigue, Life prediction, Superalloy, Fracture morphology

\section{INTRODUCTION}

In gas turbines, engineers use superalloys to achieve better efficiency and to attempt to optimize performance and efficiency. Increased turbine inlet temperatures (TIT) are aspired for reducing fuel consumption and increasing thermal efficiency. To control the energy requirement, more startup and shutdown operations are necessary. Throughout the start-up operation, the outer surface of the rotary component heats up before the inner surface. Then, compressive stress on the outer surface is created. Throughout the shut-down operation, the outer surface cools down faster. Then, tensile stress on the outer surface is created. Furthermore, the microstructure of the superalloys unavoidably becomes degraded due to operating at elevated temperatures and high rotation speeds ${ }^{1,2}$. Therefore, flexibility also becomes more important ${ }^{3}$. First-generation nickelbase superalloys have been vastly improved over time; and finally, as a solution to continual requisitions for higher turbine outputs, single-crystal and directionally-solidified superalloys were developed ${ }^{4}$. Due to their notable thermo-mechanical resistance, single-crystal and directionally-solidified Nickel-base superalloys 
are broadly used as a material for components in the hot-section of land-based gas turbines and aircraft engines ${ }^{5}$. Currently, there are many materials used at the same time with a selection made on the grounds of the constraints of the specific engineering application ${ }^{6}$. The directionally-solidified CM247 LC is one of the most commonly used superalloys for high-temperature applications, which are vastly used in the blades of gas turbines ${ }^{1,7,8}$. The appropriate mechanical properties at high temperatures are a consequence of the $\gamma^{\prime}$ precipitates in the matrix of $\gamma$ phase $^{9,10}$. The $\gamma$ and $\gamma^{\prime}$ phases are generally solid-solution strengthened. After accumulating damage during fatigue exploitations, the parameters that are of high importance include the microstructural ones such as volume fraction and coherency strains between $\gamma-\gamma^{\prime}$ and so on ${ }^{11,12}$. Numerous damage mechanisms occur in gas turbines, which can cause the failure of blades and nozzles, such as low cycle and high cycle fatigue, creep, thermo-mechanical fatigue (TMF), corrosion, foreign object damage, erosion, and oxidation ${ }^{13-17}$. Metal fatigue is one of the main mechanical failure modes in real applications 18. Due to the engine start-up and shut-down processes as well as cooling by the axial air compressor, hotsection components of a gas turbine engine experience significant thermal fluctuations, resulting in localized and small plastic strains. Thus, these components are designed such that they can be resistant to low cycle fatigue ${ }^{11,19}$. To guarantee adequate creep and fatigue resistance, the manufactures are selected directionallysolidified nickel-based superalloy materials. The low cycle fatigue failure can lead to trip the gas turbine engines and economic loss markedly in power plants and gas transmission stations, while this can also cause catastrophic damage to aero-engines ${ }^{20-22}$. Generally, stress-strain and temperature fields are the basis of the models used for LCF calculation ${ }^{23}$.

Low cycle fatigue in equiaxed and directionally-solidified Ni-based superalloys has been studied extensively over the past two decades. S.M. Seo et al. ${ }^{24}$ investigated low cycle fatigue and fracture behavior of Nibased super-alloy CM247LC at $760{ }^{\circ} \mathrm{C}$. Antolovich et al. ${ }^{25}$ investigated the low cycle fatigue behavior of René 80 at two temperatures of 871 and $982{ }^{\circ} \mathrm{C}$. It was found that when frequency decreased the fatigue life was increased. He et al. ${ }^{26}$ studied the effect of temperature on the low cycle fatigue behavior of a directionally solidified Mar-M200 superalloy from 550 to $850{ }^{\circ} \mathrm{C}$. It was found that the deformation of $\gamma$ ' precipitated phase becomes anomaly and some secondary precipitates can be observed in the matrix by increases the temperature. He et al. ${ }^{27}$ investigated the effect of temperature and strain amplitude on the dislocation structure of M963 superalloy during high-temperature low cycle fatigue. It was found that at the temperature between 700 and $800^{\circ} \mathrm{C}$, dislocation shearing $\gamma^{\prime}$ precipitates by dislocation pairs and stacking faults at medium and high strain amplitudes and at the temperature between 900 and $950^{\circ} \mathrm{C}$, dislocations by-passing $\gamma^{\prime}$ precipitates was the main deformation mode. Deng et al. ${ }^{28}$ investigated the fatigue behavior and damage mechanisms of Inconel 718 under TMF and isothermal LCF. It was found that the S-N data can be fitted by the Coffin-Manson equation under the LCF condition, and the model based on hysteresis loop energy can be predicted lifetime under TMF condition. Kashinga et al. ${ }^{29}$ investigated the effect of dwell time on the low cycle fatigue of a directionally-solidified Ni-based superalloy using both experimental and computational methods. It was shown that the misorientations between columnar grains resulted in heterogeneous deformation and localized stress concentrations, which became more severe when the loading direction was perpendicular to a solidification direction, showing the shorter lifetime observed. Mukherjee et al. ${ }^{30}$ investigated LCF behavior of Haynes 282 and its correlation with microstructure at temperature of $760{ }^{\circ} \mathrm{C}$. the results showed predict fatigue life and close agreement between calculated and measured life indicates validity of these models for the present material when plastic strain energy density based life prediction model were used. Rao et al. ${ }^{31}$ investigated low cycle fatigue behavior of Inconel 617 alloy at two temperatures conditions of room temperature and $750 \mathrm{degC}$. the results showed the cyclic hardening was occurred and also, the fatigue life decreased with increase in temperature from room temperature to 750 degC. Zhang et al. ${ }^{12}$ investigated low cycle fatigue behavior of a nickel-based single-crystal superalloy with a focus on the effect of crystal orientation and temperature. It was found depending on the strain amplitude, crystallographic orientation, and temperature either cyclic hardening or softening was observed during the low cycle fatigue. Also, low cycle fatigue life was reduced significantly by changing loading orientation from [001] to [111] or increasing temperature to $825 \operatorname{deg}$.

Despite many works that have been done to investigate the fatigue behavior and failure mechanism, the 
contact between mechanical loading, temperature, and fatigue life prediction of directionally-solidified Nibased materials actual indistinct. The present study aimed to investigate isothermal low cycle fatigue behavior in the directionally-solidified superalloy CM247 LC in the two temperatures of $600 \mathrm{degC}$ to 800 degC. In this regard, to investigate the LCF behavior the fatigue life and the fatigue degradation mechanisms were investigated and discussed in the study.

1. EXPERIMENTAL DETAILS

2. Material evaluations

The material selected for the current study was the directionally-solidified CM247 LC, which is hafnium (Hf) containing a Ni-based superalloy developed for grain turbine blades. According to the analysis results, the chemical composition of the material under study is provided in Table 1. The material was produced through vacuum induction melting. The CM247 LC superalloy was directionally-solidified into bars of $\phi 22 \times 120 \mathrm{~mm}$. The material under study went through a three-step heat-treatment process. Initially, the material was solution heat-treated at $1250 \mathrm{deg} C$ for $2.5 \mathrm{~h}$, followed by cooling. Precipitation of a uniform fine $\gamma / \gamma^{\prime}$ microstructure has resulted from this step. As the second step, the material was heat-treated at 1080 ${ }^{\circ} \mathrm{C}$ for $4.5 \mathrm{~h}$, which resulted in an optimized distribution size of $\gamma$ ' precipitates. For aging heat-treatment, the third step was applied at $860{ }^{\circ} \mathrm{C}$ for $24 \mathrm{~h}$. The mechanical and physical properties of the cast directionallysolidified CM247 LC are presented in Table 2. The processing and development of the directionally-solidified superalloy CM247 LC are reported in Ref. ${ }^{32}$. Generally, in the DS and SC Ni-based materials, the mechanical characteristics are extremely dependent on the ?' precipitates' specifications including size, volume fraction, and distribution ${ }^{33,34}$. For the examination of microstructures, the specimens for metallographic examination were cut from the casted material through the EDM process and then the standard procedure of polishing was performed on the samples. The etched process was carried out with a solution of lactic acid, nitric acid, and Hydrogen fluoride regent for a time of $120 \mathrm{~s}$ and at a voltage of $7 \mathrm{~V}$. The OLYMPUS optical microscope and a TESCAN field emission scanning electron microscope (FE-SEM) were used to examine the fractured surfaces. For this purpose, a rod specimen with dimensions of $15 \mathrm{~mm}$ in diameter and $10 \mathrm{~mm}$ in length was prepared. For statistical analysis of the metallurgical data of the SEM images an image analysis software (metallographical image processing (MIP) package) application was used. The optical micrographs of the microstructures in the longitudinal and traverse sections of the grain axis of the CM247 LC superalloy are shown in Fig. 1(a) and (b), respectively. As can be observed, the microstructure involves both primary and secondary dendrites as well as inter-dendritic regions. In Fig. 1(b), the mean of primary dendrite arm spacing size is $250 \mu \mathrm{m}$ and the mean of secondary dendrite arm spacing size is $210 \mu \mathrm{m}$. Furthermore, some distributed microstructural features like eutectic $\gamma / \gamma^{\prime}$ are observed in the white-colored. The SEM micrographs of the microstructure are shown in Fig. 2. Four EDS points were taken from formed (HF/Ta) $\mathrm{C}, \gamma / \gamma^{\prime}$ eutectic phase, $\gamma$ matrix, and $\gamma^{\prime}$, respectively. The EDS results are shown in Fig. 2. As can be seen, $\gamma^{\prime}$ intermetallic phase is distributed in a matrix of $\gamma$. The average $\gamma^{\prime}$ precipitate phase fraction was obtained as $62 \%$ and the average size of the $\gamma^{\prime}$ precipitate was achieved as $0.5 \mu \mathrm{m}$. The grain boundaries consisted of the main percentage of primary $\gamma / \gamma^{\prime}$ eutectic phase and only a small percentage within the grains.

\section{Low cycle fatigue test procedure}

Directionally-solidified CM247 LC was used after the heat treatment procedures. The present study used the button-head specimen for the LCF test. The LCF specimens were machined with an extensometer gauge section of $5.75 \mathrm{~mm}$, with $27 \mathrm{~mm}$ in length. The low cycle fatigue test specimen and its schematic are shown in Fig. 3. All specimens used in this study were designed according to ASTM standard E606, considering the fact that the solidification direction is parallel to the loading axis (along [001] crystal orientation with a misorientation less than $\pm 10^{\circ}$ ) and they were machined from casted and heat-treated material. The ratio of the gage section area to the gage section diameter is a vital factor in ASTM E606 strain-controlled low cycle fatigue test standard, which is obtained by the LCF specimens under study. All casted specimens had the same conditions and the same casting parameters. Also, before the LCF test, all specimens were polished using $\mathrm{SiC}$ sandpaper to eliminate the surface machining defects and marks. Afterward, a visual inspection procedure was carried out to ensure that the residual marks were cleaned for each fatigue specimen. Finally, 
specimens were cleaned by acetone and dried by air. In this study, the strain-controlled low cycle fatigue tests were performed at the two temperature conditions of $600{ }^{\circ} \mathrm{C}$ and $800{ }^{\circ} \mathrm{C}$. All low cycle fatigue tests were performed using a100 $k N$ servo-hydraulic testing machine (Instron Co.), where the machine had a low-profile load cell with a resolution of $\pm 0.2 \mathrm{kN}$. Two N-type thermocouples with a resolution of $\pm 2 C$ were welded to the gage section in order to monitor the temperature gradient. A radio frequency induction system was used to apply heat to the specimen, while a PID controller by using the closed-loop feedback control was kept the LCF specimen temperature. Approximately 2 minutes after the set-point temperature became stable, the LCF tests were started. The RF induction system applied maximum temperature on the gage section of LCF test specimens. The mechanical strain amplitudes were $0.4,0.6,0.8$, and $1 \%$. Therefore, symmetrical triangular waveform and a constant total strain amplitude were kept throughout the totallyreversed loading conditions $(R=-1)$. In each LCF test, temperature and mechanical strain amplitude are different. The strain rates were held constant during loading and unloading slopes. Strain $(\mathrm{mm} / \mathrm{mm})$, Force $(\mathrm{N})$, displacement $(\mathrm{mm})$, temperature $\left({ }^{\circ} \mathrm{C}\right)$, and the values of the peak forces were monitored and recorded for each cycle. Subsequently, to determine failure, the stress history was periodically analyzed. Fig. 4 shows the mechanical strain amplitudes and temperatures applied to the LCF tests.

\section{MODELING WORK}

2. Low cycle fatigue life

A strain-controlled fatigue curve includes elastic and plastic strain data ${ }^{35}$. In isothermal problems, the Basquin's equation (cyclic stress) and the Coffin-Manson equation (cyclic plastic strain) use the elastic and plastic strain data, respectively ${ }^{36}$. The Basquin's equation is more appropriate and it is used for the high cycle fatigue $(\mathrm{HCF})$ regime ${ }^{37,38}$ :

$\frac{\Delta \varepsilon_{e}}{2}=\frac{\sigma^{\prime} f}{E}\left(2 N_{f}\right)^{b}(1)$

On the other hand, the Coffin-Manson equation is used for the low cycle fatigue (LCF) regime and defines the reliance of fatigue life under isothermal loading on plastic strain amplitude ${ }^{39,40}$ :

$\frac{\varepsilon_{p}}{2}=\varepsilon_{f}^{\prime}\left(2 N_{i}\right)^{c}(2)$

Where $\varepsilon_{\mathrm{p}}$ is the plastic strain amplitudes, $\mathrm{c}$ is the strain ductility exponent, $\varepsilon_{f}^{\prime}$ is the strain ductility coefficient, and $\mathrm{N}_{\mathrm{i}}$ is the cycle to crack initiations. Nevertheless, sometimes in the LCF problems, the Coffin-Manson law has an error in fatigue life prediction, which is assumed because of the unsteady loading condition ${ }^{41}$ and unexpected failure modes ${ }^{42,43}$. As a consequence, the Coffin-Manson equation is not suitable for predicting the lifetime for LCF, when a variable likewise temperature is introduced into the problem ${ }^{44}$. Furthermore, a suitable model for fatigue life prediction has to accurately estimate the material's fatigue life, and it should also be evaluating fatigue property. Nevertheless, the Basquin equation is suitable for calculating the material's fatigue behavior based on the cyclic stress amplitude, while the Coffin-Manson equation is suitable for assessing the material's fatigue property based on the plastic strain. Therefore, neither of them would be suitable for the evaluation of the integrated fatigue property. Thus, a new model is identified and developed based on hysteresis energy, which is presented below ${ }^{45}$ :

$D_{i}=\left(\frac{W_{i}}{W_{0}}\right)^{\beta}(3)$

$D=\sum_{i=1}^{N_{f}} D_{i}=\sum_{i=1}^{N_{f}}\left(\frac{W_{i}}{W_{0}}\right)^{\beta}=1(4)$

Where, $D_{i}$ and $W_{i}$ are the damage parameter and the hysteresis energy of the $i_{\text {th }}$ cycle, respectively. $W_{0}$ and $\mathrm{b}$ are material constants, and $\mathrm{W}_{0}$ is the fundamental fatigue toughness. The relation between plastic strain and hysteresis energy is shown in Fig. 5. As can be observed, $\mathrm{W}_{\mathrm{i}}$ is the stress-strain hysteresis loop area for each cycle, as shown with the red zone, and the value of $\Delta \varepsilon_{\mathrm{p}} \cdot \Delta \sigma$ is the gray zone. The fatigue damage capacity of the material is defined by $\mathrm{W}_{0}$. The $\mathrm{b}$ parameter is the damage transition exponent. It is described as the ability to transform mechanical work into operative damage to the materials which, in other words, is described as the susceptibility that the damage reacts to the diversity of loading conditions 
45. Moreover, the fatigue damage is denoted by D. In this model, when fatigue damage D equals 1 , the material fails. The simplified model is written as follows:

$D=\sum_{i=1}^{N_{f}} D_{i}=\sum_{i=1}^{N_{f}}\left(\frac{W_{s}}{W_{0}}\right)^{\beta}=1(5)$

Where $\mathrm{W}_{\mathrm{s}}$ is the half life cycle hysteresis energy, the Eq. (5) can be converted into the Coffin-Manson equation as the following:

$W_{s}=W_{0} \times N_{f}^{\frac{-1}{\beta}}$

However, the $\Delta \sigma / 2, \Delta \varepsilon_{\mathrm{p}} / 2$, and $\mathrm{W}_{\mathrm{S}}$ are obtained from the fatigue data.

\section{RESULTS AND DISCUSSIONS}

The results and discussion of isothermal low cycle fatigue behavior in the directionally-solidified CM247 LC superalloy is presented in this section. Based on the LCF test procedure under two temperature conditions of $600{ }^{\circ} \mathrm{C}$ and $800{ }^{\circ} \mathrm{C}$, the low cycle fatigue behavior of the directionally-solidified CM247 LC superalloy was investigated. The low cycle fatigue data obtained by experimental tests as well as the relationship between half-life stress range, cycles to failure under constant strain amplitude, degree of softening, and the two temperature conditions are presented in Table 3. The values of stress range amplitude are obtained from the hysteresis curve of the half-life cycle. Based on the obtained data of the Table 3, once the strain amplitude is increased, the stress range is increased and the fatigue life (cycle to failure) is decreased.

A set of strain-controlled experiments were performed to evaluate the influence of temperature on the fatigue life under axial loading in the direction along the solidification axis. In the low cycle fatigue, the hysteresis loop (cyclic stress-strain behavior) indicates the relationship between the strain range and the stress range for each cycle. The stress-strain hysteresis curves can be achieved by using the companion method which is connecting the vertices of the stable or half-life cycle loops at different strain amplitudes. This method is used to determine the stable cyclic stress-strain behavior of the material throughout the low cycle fatigue test. The hysteresis loops for LCF tests are plotted in Fig. 6 under two temperature conditions and the mechanical strain amplitudes of 0.4, 0.6, 0.8, and $1 \%$. As shown in Fig. 6, at the temperature condition of $600{ }^{\circ} \mathrm{C}$, at the strain amplitude of $0.4 \%$ the peak stress value decreased from $994 \mathrm{MPa}$ at the first cycle to $831 \mathrm{MPa}$ at the half-life cycle, at the strain amplitude of $0.6 \%$ it decreased from $1059 \mathrm{MPa}$ at the first cycle to $880 \mathrm{MPa}$ at the half-life cycle, at the strain amplitude of $0.8 \%$ it decreased from $1144 \mathrm{MPa}$ at the first cycle to $1007 \mathrm{MPa}$ at the half-life cycle, and the strain amplitude of $1 \%$ it declined from $1205 \mathrm{MPa}$ at the first cycle to $1058 \mathrm{MPa}$ at the half-life cycle. At the temperature condition of $800{ }^{\circ} \mathrm{C}$, at the strain amplitude of $0.4 \%$, the peak stress value decreased from $914 \mathrm{MPa}$ to $655 \mathrm{MPa}$ from the first cycle to the half-life cycle, at the strain amplitude of $0.6 \%$ it decreased from $963 \mathrm{MPa}$ to $748 \mathrm{MPa}$ from the first cycle to the half-life cycle, at the strain of $0.8 \%$ it decreased from $1095 \mathrm{MPa}$ to $836 \mathrm{MPa}$ from the first cycle to the half-life cycle, and at the strain amplitude of $1 \%$, it declines from $1130 \mathrm{MPa}$ to $825 \mathrm{MPa}$ from the first cycle to the half-life cycle. The hysteresis loops showed the stress value is increased with increasing the strain amplitude, and while the temperature is increased from $600{ }^{\circ} \mathrm{C}$ to $800{ }^{\circ} \mathrm{C}$, of all strain amplitudes the temperatureinduced softening is observed and the material CM247 LC shows a softening behavior. Therefore, the cyclic stress-strain curves showed that the cyclic softening occurs at both temperature conditions at all the strain amplitudes (Fig. 6). A comparison of the experimental results, depicted in Fig. 6, for LCF tests, reveals that the fatigue life is decreased when the temperature shifts from $600{ }^{\circ} \mathrm{C}$ to $800{ }^{\circ} \mathrm{C}$ for all strain amplitudes. The occurrence of the cyclic softening behavior in precipitation-hardened alloys depends on some reasons which are the formation of dislocation networks at the $\gamma / \gamma^{\prime}$ interface, shearing of precipitates, dissolution of precipitates, and coarsening of the precipitates ${ }^{11,46,47}$. The cyclic stress-strain hysteresis loops obtained with the experimental test data for two temperature conditions indicated that, at a lower temperature, the material had higher stiffness when the load was aligned along the solidification direction of the material. The plastic strain range can be obtained from the width of the hysteresis loop (Fig. 5). For an assumed strain amplitude, the plastic strain amplitude increased with transferred the temperature from $600{ }^{\circ} \mathrm{C}$ to $800{ }^{\circ} \mathrm{C}$. 
Based on the hysteresis loops obtained from the experimental test of CM247 LC, the degree of softening is determined using the Eq. (7) as follows ${ }^{48}$ :

Degree of softening $=\frac{\left(\frac{\text { stress range }}{2} \text { at half life cycle }\right)-\left(\frac{\text { stress range }}{2} \text { at the first cycle }\right)}{\frac{\text { stress range }}{2} \text { at the first cycle }}(7)$

The degrees of softening at the half-life cycle for all LCF tests are presented in Table 3. The variations of the degree of softening vs strain amplitudes are shown in Fig. 7. For temperature condition of $600{ }^{\circ} \mathrm{C}$, the degree of softening at the strain amplitude of $0.4 \%$ to $1 \%$ is increased from $18.2 \%$ to $23.1 \%$, and for temperature condition of $800{ }^{\circ} \mathrm{C}$, is increased from $20.6 \%$ to $39.8 \%$. As can be observed, that through increasing the strain amplitude the degree of softening increased for all strain amplitudes and temperatures, and also, the degree of softening is increased with increasing the temperature from $600{ }^{\circ} \mathrm{C}$ to $800{ }^{\circ} \mathrm{C}$.

The cyclic stress amplitude versus the number of cycles at different strain amplitudes is called the cyclic stress response that is a significant parameter in low cycle fatigue, and describes the stress amplitude at the final stress level, while also showing the deformation throughout the cyclic loading of the material. Cyclic stress response under two temperature conditions for individual strain amplitudes of the directionally-solidified CM247 LC is shown in Fig. 8. Peak stress values are used to show the cyclic stress response of the material. The cyclic stress response showed at both temperature conditions and all the strain amplitudes of the CM247 LC showed a normal cyclic response and by increasing the strain amplitude the cyclic stress amplitude is increased. Throughout the cyclic loading, the material reveals softening behavior until the time when the overload step occurs. As shown in Fig. 8 at both temperatures and all the strain amplitudes, curves indicate that by increasing the strain amplitude the cyclic stress amplitude is also increased. For both temperature conditions, the cyclic softening was seen throughout the test process and followed by a rapid drop in the stress due to the initiation of microcracks and their growth leading to final failure. Also, when the temperature transfers from $600{ }^{\circ} \mathrm{C}$ to $800{ }^{\circ} \mathrm{C}$, the curves show that the stresses are steadily decreasing. Furthermore, as shown in Fig. 8, as the softening increases the lifespan would be less. The cyclic stress response hypothesis describes that cyclic softening is expected in the materials with $\mathrm{S}_{\mathrm{UTS}} / \mathrm{S}_{\mathrm{YS}}$ less than 1.4 which is in line with the hypothesis. When gradual strain softening is occurred at the lower temperatures, rapid strain softening at higher temperatures is observed and the degree of work hardening $\left(\mathrm{S}_{\mathrm{UTS}} / \mathrm{S}_{\mathrm{YS}}\right.$ ratio) is higher at 800 ${ }^{\circ} \mathrm{C}$ compared with that at $600{ }^{\circ} \mathrm{C}$. In the precipitated hardening superalloys, the dislocation-precipitate interaction mechanisms determine the cyclic stress response behavior ${ }^{12}$. While the principal mechanism is precipitate shearing, the initial hardening is mostly followed by a period of softening, or only softening can be observed.

In order to predict fatigue life and evaluate the low cycle fatigue behavior, the Coffin-Manson model, based on plastic deformation, and a model based on the hysteresis energy criterion is used. The values of plastic strain amplitude throughout the cyclic deformation are shown in Fig. 9 and the hysteresis energy during cyclic deformation for all LCF tests are shown in Fig. 10. The values of plastic strain amplitude throughout the cyclic deformation (Fig. 9) demonstrated that the plastic strain amplitudes increase after a small cycling interval for all strain amplitudes at $600{ }^{\circ} \mathrm{C}$ and $800{ }^{\circ} \mathrm{C}$. The results obtained from Fig. 9 show a monotonic increase in the plastic strain amplitude with the increasing number of cycles, indicating the occurrence of cyclic softening in the directionally-solidified CM247 LC. Based on the obtained results from Fig. 10, it can be seen that hysteresis energy reveals cyclic stability right after a small cycling interval for all strain amplitudes, indicating a similar behavior to that of the plastic strain amplitude.

The fitted curves of the fatigue life prediction models based on the Coffin-Manson equation for obtained results from Fig. 9 are plotted in Fig. 11. Following the experimental LCF data, the fatigue lifetime versus plastic strain amplitude is fitted following the Coffin-Manson law (Fig. 11). The values of $\mathrm{R}^{2}$ are fitted based on the Coffin-Manson equation and are 0.91 and 0.95 under $600{ }^{\circ} \mathrm{C}$ and $800{ }^{\circ} \mathrm{C}$ LCF test conditions, respectively. A comparison of plastic strain amplitude-life relationship at the two temperature conditions indicates that the fatigue life decreased by transferring the temperature from $600{ }^{\circ} \mathrm{C}$ to $800{ }^{\circ} \mathrm{C}$. The fitted curves of the fatigue life prediction models based on the hysteresis energy model for the obtained results from Fig. 10 are plotted in Fig. 12. Following the experimental LCF data, the fatigue lifetime versus hysteresis 
energy is fitted according to the hysteresis energy model and plotted in Fig. 12. The values of $\mathrm{R}^{2}$ are fitted based on the hysteresis energy model equation and are obtained as 0.92 and 0.94 under $600{ }^{\circ} \mathrm{C}$ and $800{ }^{\circ} \mathrm{C}$ LCF test conditions, respectively. This hysteresis energy model shows good ability to calculate the fatigue life of low cycle fatigue mechanism at high-temperature conditions. The plastic strain amplitude-life and hysteresis energy-life relationship at both temperatures showed that the fatigue life is decreased when the temperature increases.

After LCF testing and in order to investigate the failure mechanisms in this study, fracture surfaces of the fractured low cycle fatigue test specimens were separately examined and analyzed using field emission scanning electron microscopy (FE-SEM). The fracture surface examination using SEM for the low cycle fatigue specimens of the two temperature test conditions are shown in Fig. 13. As shown in Fig. 13, the intergranular cracking was observed in the fractured surface of the specimen for LCF test specimens. Cavities and inter-granular cracks were observed during low cycle fatigue tests performed in all specimens. According to the examination of all the LCF specimens, fracture surfaces were generally perpendicular to the loading axis. Due to the loading of LCF specimens along the solidification direction, the fracture surface features, depicted in Fig. 13, were conceivably caused by inter-granular cracking. Moreover, the fatigue marks in fractured LCF test specimens and the final stage of the fatigue fracture region are shown in Fig. 14 and Fig. 15, respectively. As shown in Fig. 14 the fatigue striations, as well as the cleavage facets with intergranular cracks, appear on the fractured surface. The striations are defined and uniformly spaced at high strain amplitude and high temperature compared to those at low strain amplitude and low temperature. At low temperatures, the striations are not uniform and appear partially deformed or ductile. The rapid decline in peak stress amplitude observed before the failure can mostly be attributed to the fast propagation and ultimate coalescence of cracks, resulting in a decrement in the load-bearing capacity. Furthermore, once the temperature and stress amplitude are increased the decrease in the area of fatigue fracture would be observed. The reason for this phenomenon is the more inter-striation spacing as compared to that at lower strain amplitudes and temperatures, which results from the high cyclic stress response, and so, fewer cycles would fit in the mentioned area. The rapid fracture surfaces of the LCF test specimens of strain amplitudes of $0.6 \%$ and $1 \%$ at both temperature conditions are shown in Fig.15. As demonstrated in these figures, some dimples and plastic deformation marks are observed in the rapidly fractured region. The fracture region was representative of the ductile fracture mechanism at all strain amplitudes at both temperatures. Comparison of fracture surfaces of two temperature conditions and all strain amplitudes showed similar behaviors in the fracture characteristics.

\section{CONCLUSIONS}

Isothermal low cycle fatigue behavior of the directionally-solidified CM247 LC Ni-based superalloy is studied under two temperature conditions of $600{ }^{\circ} \mathrm{C}$ and $800{ }^{\circ} \mathrm{C}$. The main conclusions obtained in the current study can be written as follows:

1. Comparison of low cycle fatigue under two temperature conditions of $600{ }^{\circ} \mathrm{C}$ and $800{ }^{\circ} \mathrm{C}$ showed that the fatigue life decreases with increased temperature from $600{ }^{\circ} \mathrm{C}$ to $800{ }^{\circ} \mathrm{C}$.

2. The cyclic hysteresis loops obtained in the experimental tests for two temperature conditions of LCF tests showed that the material had higher stiffness in lower temperatures, and with changing temperature from $600{ }^{\circ} \mathrm{C}$ to $800{ }^{\circ} \mathrm{C}$, a cyclic softening was observed.

3. The results of plastic strain amplitude tests showed a monotonic increase in the plastic strain amplitude with the increasing number of cycles, indicating that cyclic softening occurred in the LCF test process.

4. The failure modes that occurred on LCF specimens are inter-granular fractures, and similar striation morphologies were observed in LCF test specimens.

5. The fatigue life of the directionally-solidified CM247 LC under the isothermal LCF test condition can be predicted by the Coffin-Manson and hysteresis energy model.

\section{ACKNOWLEDGEMENTS}

The first author would like to expresses his great appreciation to Mrs. Z. Khoshkhou-Gilavaie from the 
University of Tehran for editorial helps that greatly improved the manuscript.

\section{REFERENCES}

1. Balam SSK, Tamilselvi M, Mondal AK, Rajendran R. An investigation into the cracking of platinum aluminide coated directionally solidified CM247 LC high pressure nozzle guide vanes of an aero engine.Engineering Failure Analysis. 2018;94:24-32.

2. Mart, iacute, nez-Esnaola JM, et al. Crack Initiation in an Aluminide Coated Single Crystal During Thermomechanical Fatigue. In: Verrilli MJ, Castelli MG, eds. West Conshohocken, PA: ASTM International; 1996:68-81.

3. Schlesinger M, Seifert T, Preussner J. Experimental investigation of the time and temperature dependent growth of fatigue cracks in Inconel 718 and mechanism based lifetime prediction. International Journal of Fatigue. 2017;99:242-249.

4. Furrer D, Fecht H. Ni-based superalloys for turbine discs.JOM. 1999;51(1):14-17.

5. Caron P, Khan T. Evolution of Ni-based superalloys for single crystal gas turbine blade applications. Aerospace Science and Technology.1999;3(8):513-523.

6. Slámečka K, Pokluda J, Kianicová M, Horníková J, Obrtlík K. Fatigue life of cast Inconel 713LC with/without protective diffusion coating under bending, torsion and their combination. Engineering Fracture Mechanics. 2013;110:459-467.

7. Rajendran R, Ganeshachar MD, Jivankumar, Mohana Rao T. Condition assessment of gas turbine blades and coatings. Engineering Failure Analysis. 2011;18(8):2104-2110.

8. Bhaumik SK, Sujata M, Venkataswamy MA, Parameswara MA. Failure of a low pressure turbine rotor blade of an aeroengine. Engineering Failure Analysis. 2006;13(8):1202-1219.

9. Nie JF, Liu ZL, Liu XM, Zhuang Z. Size effects of $\gamma^{\prime}$ precipitate on the creep properties of directionally solidified nickel-base super-alloys at middle temperature. Computational Materials Science. 2009;46(2):400406.

10. Xia PC, Yu JJ, Sun XF, Guan HR, Hu ZQ. Influence of $\gamma^{\prime}$ precipitate morphology on the creep property of a directionally solidified nickel-base superalloy. Materials Science and Engineering: A.2008;476(1):39-45.

11. Rai RK, Sahu JK, Das SK, Paulose N, Fernando DC, Srivastava C. Cyclic plastic deformation behaviour of a directionally solidified nickel base superalloy at $850{ }^{\circ} \mathrm{C}$ : Damage micromechanisms. Materials Characterization. 2018;141:120-128.

12. Zhang L, Zhao LG, Roy A, Silberschmidt VV, McColvin G. Low-cycle fatigue of single crystal nickelbased superalloy - mechanical testing and TEM characterisation. Materials Science and Engineering: A.2019;744:538-547.

13. Qu S, Fu CM, Dong C, Tian JF, Zhang ZF. Failure analysis of the 1st stage blades in gas turbine engine. Engineering Failure Analysis.2013;32:292-303.

14. Salehnasab B, Poursaeidi E, Mortazavi SA, Farokhian GH. Hot corrosion failure in the first stage nozzle of a gas turbine engine. Engineering Failure Analysis. 2016;60:316-325.

15. Kumari S, Satyanarayana DVV, Srinivas M. Failure analysis of gas turbine rotor blades. Engineering Failure Analysis.2014;45:234-244.

16. Carter TJ. Common failures in gas turbine blades. Engineering Failure Analysis. 2005;12(2):237-247.

17. Salehnasab B, Poursaeidi E. Mechanism and modeling of fatigue crack initiation and propagation in the directionally solidified CM186 LC blade of a gas turbine engine. Engineering Fracture Mechanics.2020;225:106842. 
18. Ralph I. Stephens AF, Robert R. Stephens, Henry O. Fuchs. Metal Fatigue in Engineering. 2nd Edition ed: Wiley 2000.

19. Sahu JK, Ravi Kumar B, Das SK, Paulose N, Mannan SL. Isothermal high temperature low cycle fatigue behavior of Nimonic-263: Influence of type I and type II hot corrosion. Materials Science and Engineering: A. 2015;622:131-138.

20. Prasad K, Sarkar R, Ghosal P, Kumar V, Sundararaman M. High temperature low cycle fatigue deformation behaviour of forged IN 718 superalloy turbine disc. Materials Science and Engineering: A.2013;568:239245.

21. Cano S, Rodríguez JA, Rodríguez JM, et al. Detection of damage in steam turbine blades caused by low cycle and strain cycling fatigue.Engineering Failure Analysis. 2019;97:579-588.

22. Gao H, Fei C, Bai G, Ding L. Reliability-based low-cycle fatigue damage analysis for turbine blade with thermo-structural interaction.Aerospace Science and Technology. 2016;49:289-300.

23. Gustafsson D, Moverare JJ, Johansson S, et al. Influence of high temperature hold times on the fatigue crack propagation in Inconel 718. International Journal of Fatigue. 2011;33(11):1461-1469.

24. Seo SM, Kim IS, Jo CY. Low Cycle Fatigue and Fracture Behavior of Nickel-Base Superalloy CM247LC at $760^{\circ} \mathrm{C}$. Materials Science Forum.2004;449-452:561-564.

25. Antolovich SD, Liu S, Baur R. Low cycle fatigue behavior of René 80 at elevated temperature. Metallurgical Transactions A.1981;12(3):473-481.

26. He Z, Zhang Y, Qiu W, Shi H-J, Gu J. Temperature effect on the low cycle fatigue behavior of a directionally solidified nickel-base superalloy. Materials Science and Engineering: A.2016;676:246-252.

27. He L, Zheng Q, Sun X, et al. Effect of Temperature and Strain Amplitude on Dislocation Structure of M963 Superalloy during High-Temperature Low Cycle Fatigue. MATERIALS TRANSACTIONS.2006;47(1):67-71.

28. Deng W, Xu J, Hu Y, Huang Z, Jiang L. Isothermal and thermomechanical fatigue behavior of Inconel 718 superalloy. Materials Science and Engineering: A. 2019;742:813-819.

29. Kashinga RJ, Zhao LG, Silberschmidt VV, et al. Low cycle fatigue of a directionally solidified nickel-based superalloy: Testing, characterisation and modelling. Materials Science and Engineering: A. 2017;708:503-513.

30. Mukherjee S, Barat K, Sivaprasad S, Tarafder S, Kar SK. Elevated temperature low cycle fatigue behaviour of Haynes 282 and its correlation with microstructure - Effect of ageing conditions.Materials Science and Engineering: A. 2019;762:138073.

31. Rao CV, Srinivas NCS, Sastry GVS, Singh V. Low cycle fatigue, deformation and fracture behaviour of Inconel 617 alloy. Materials Science and Engineering: A. 2019;765:138286.

32. K. Harris GLE, R.E. Schwer. M. Mar, 247 derivations - Cm 247 Lc Ds Alloy Cmsx single crystal alloys properties \& performance, Superalloys. In: Cannon-Muskegon Corporation 1984.

33. Zhao JC, Westbrook JH. Ultrahigh-Temperature Materials for Jet Engines. MRS Bulletin. 2003;28(9):622630.

34. Fan YS, Yang XG, Shi DQ, Han SW, Li SL. A quantitative role of rafting on low cycle fatigue behaviour of a directionally solidified Ni-based superalloy through a cross-correlated image processing method.International Journal of Fatigue. 2020;131:105305.

35. Radonovich D, Gordon AP. Methods of Extrapolating Low Cycle Fatigue Data to High Stress Amplitudes. 2008(43154):159-168. 
36. Daubenspeck BR, Gordon AP. Extrapolation Techniques for Very Low Cycle Fatigue Behavior of a Ni-base Superalloy. Journal of Engineering Materials and Technology. 2011;133(2):021023-021023-021029.

37. Nagarjuna S, Srinivas M, Balasubramanian K, Sarmat DS. Effect of alloying content on high cycle fatigue behaviour of Cu?Ti alloys.International Journal of Fatigue. 1997;19(1):51-57.

38. Lai J, Lund T, Ryden K, Gabelli A, Strandell I. The fatigue limit of bearing steels - Part I: A pragmatic approach to predict very high cycle fatigue strength. International Journal of Fatigue.2012;38:155-168.

39. Praveen KVU, Singh VJM, A MT. Effect of Cold Rolling on the Coffin-Manson Relationship in LowCycle Fatigue of Superalloy IN718. 2008;39(1):79-86.

40. Suresh S. Fatigue of Materials. 2 ed. Cambridge: Cambridge University Press; 1998.

41. Liu R, Zhang ZJ, Zhang P, Zhang ZF. Extremely-low-cycle fatigue behaviors of $\mathrm{Cu}$ and $\mathrm{Cu}-\mathrm{Al}$ alloys: Damage mechanisms and life prediction. Acta Materialia. 2015;83:341-356.

42. Nip KH, Gardner L, Elghazouli AY. Cyclic testing and numerical modelling of carbon steel and stainless steel tubular bracing members. Engineering Structures. 2010;32(2):424-441.

43. Xue L. A unified expression for low cycle fatigue and extremely low cycle fatigue and its implication for monotonic loading.International Journal of Fatigue. 2008;30(10):1691-1698.

44. Kang L, Ge H. Predicting Ductile Crack Initiation of Steel Bridge Structures Due to Extremely LowCycle Fatigue Using Local and Non-Local Models. Journal of Earthquake Engineering. 2013;17(3):323-349.

45. Shao CW, Zhang P, Liu R, Zhang ZJ, Pang JC, Zhang ZF. Low-cycle and extremely-low-cycle fatigue behaviors of high-Mn austenitic TRIP/TWIP alloys: Property evaluation, damage mechanisms and life prediction. Acta Materialia. 2016;103:781-795.

46. Miao J, Pollock TM, Wayne Jones J. Crystallographic fatigue crack initiation in nickel-based superalloy Rene 88DT at elevated temperature. Acta Materialia. 2009;57(20):5964-5974.

47. Wang XG, Liu JL, Jin T, et al. Deformation mechanisms of a nickel-based single-crystal superalloy during low-cycle fatigue at different temperatures. Scripta Materialia. 2015;99:57-60.

48. Plumbridge WJ, Dalski ME, Castle PJ. HIGH STRAIN FATIGUE OF A TYPE 316 STAINLESS STEEL. Fatigue 83 Fracture of Engineering Materials 83 Structures. 1980;3(2):177-188.

\section{Hosted file}

Figures.docx available at https://authorea.com/users/353500/articles/477351-low-cyclefatigue-behavior-and-fracture-mechanism-of-a-directionally-solidified-cm247-lcsuperalloy

\section{Hosted file}

Tables.docx available at https://authorea.com/users/353500/articles/477351-1ow-cyclefatigue-behavior-and-fracture-mechanism-of-a-directionally-solidified-cm247-lcsuperalloy 